\title{
Towards Urban High-technolgy Clusters: An International Comparison
}

\author{
Júlia Bosch, Laura Capel, François Cougoule, Gissel Ferrari and Sergi Solanas
}

\author{
Julia Bosch, Institut d'Estudis Territorials, Universitat Pompeu Fabra, Barcelona, Spain \\ (julia.bosch@ietcat.org)
}

Laura Capel, Institut d'Estudis Territorials, Universitat Pompeu Fabra - Generalitat de Catalunya, Barcelona, Spain / Autonomous University of Barcelona, Barcelona, Spain (laura.capel@ietcat.org)

François Cougoule, Institut d'Estudis Territorials, Universitat Pompeu Fabra, Barcelona, Spain (francois.cougoule@ietcat.org)

Olga Gissel Ferrari, Institut d'Estudis Territorials, Universitat Pompeu Fabra, Barcelona, Spain / Department of Applied Economics, Autonomous University of Barcelona, Spain (gissel.ferrari@ietcat.org)

Sergi Solanas, Institut d'Estudis Territorials, Universitat Pompeu Fabra, Barcelona, Spain / Adjunct Faculty of Microeconomics (Industrial Organization), Department of Economics and Business, Universitat Pompeu Fabra, Barcelona, Spain (sergi.solanas@ietcat.org)

\begin{abstract}
This paper presents the results of a comparative study of 23 urban or regional high-technology clusters (media, ICT, energy, biotechnology) all over the world, analyzing how they were created, how they are managed and how they operate, and the strategies followed to improve and excel in their fields of action. Special attention is given to issues related to descriptive aspects, R\&D, performance of the clusters, location factors and incentives to attract companies. The empirical analysis applied to the identified clusters was done through a questionnaire sent to the representatives of the cluster's management. When analyzing the data, the study has combined quantitative and qualitative methods, depending on the information to be processed. The data collection was done through a selection of indicators chosen in order to cover the different elements that cluster literature coincide in consider essential to develop a competitive economic cluster in urban regions. The main obstacle we find with the information available to carry out this study has been its heterogeneity and different quality of the data. 22@Barcelona appears to be in a good position to compete with other excelling clusters, but it still needs to improve in areas such as financial supply for R\&D and start-ups and coordination between the different actors involved in urban economic development. Our research also contributes to the discussion on the role of public institutions in the cluster development policies. In the clusters studied here, especially in 22@Barcelona, we have seen that a capable and resourceful public administration can determine the success of the cluster initiative.
\end{abstract}

Keywords: cluster initiatives, urban spaces, regional policies, high-technology

\section{Introduction}

Clusters, understood as being interconnected geographic concentrations of businesses and institutions of a specific field, have a long research tradition in urban and regional 
economics which has led to numerous literature on the subject ${ }^{1}$ and based on diverse economic activities (from automotive industries to food or textile) ${ }^{2}$.

In this paper we focus in one specific type of cluster that emerged with the growth of the economy based in the information and communication technologies, which usually grow in metropolitan areas with industrial means and know-how. The economy of Internet has, for example, intensified the high density of companies in cities such as San Francisco, New York and Los Angeles, following the same geographic patterns as other innovations in the past (Leaner and Storper 2001). The starting point is usually the establishment of a small number of central institutions characterized by their strong network relations among companies and between the labour market and companies, because of their industrial environment and because of a circular and accumulative advantage as a result of the generation of external economies in these places (Storper and Walker 1989).

The success of some of this 'technological clusters' has lead to numerous initiatives of a similar scope and also to many research trying to understand how these clusters work and what the key to success of them is (Bresnahan et al. 2001). In this sense, one strand of research focus on the so-called 'cluster-based initiatives' and tries to discern the effectiveness of public driven innovative clusters at regional and local level (Burfitt et al. 2007, Fromhold-Eisebith 2005, Desrochers and Sautet 2004).

A good case of study to analyze such research strand is the 22@Barcelona, a public driven cluster initiative of the Barcelona municipality to transform an old industrial area into an innovative district for the concentration of intensive knowledgebased activities. In order to position it in the international scene, we follow a comparative methodology to try establishing the success elements of various innovation clusters in the world.

Literature referring to the comparison of clusters shows that this type of exercise has been carried out mainly in North America and Europe. In the first case, they have been led by Michael Porter and the Institute for Strategy and Competitiveness of the Harvard Business School (www.isc.hbs.edu/econ-clusters.htm). Their main projects include 'The Cluster Mapping Project' and 'The Cluster Meta-Study'. By using regional data, existing publications referring to clusters and statistical techniques, they analyze the regional economic profiles and their performance over time, with special emphasis on clusters. To do this, they use a model to enable them to collect information in a tabulated manner and compare the variables. The model has been taken into consideration in the design of the questionnaire used in this work.

In Europe, one of the most important strategies is 'The Cluster Initiative Green Book' (Sölvell, Lindtqvist and Ketels 2003) developed by 'The Competitiveness Institute', a non-profit association formed by professionals of clusters working in cooperation with Michael Porter ${ }^{3}$. 500 clusters have been identified throughout the world, chiefly in Europe, North America, New Zealand and Australia, 238 of which have been interviewed through an online survey. This study establishes a series of characteristics, which in spite of the typological diversity of the clusters, seem often to appear in all cases: initiatives are more frequent in developed countries and in transition economies, and the majority are focused on technology-intensive areas such as

\footnotetext{
${ }^{1}$ Some widely known classical references are Krugman (1991), Porter (1998) and Saxenian (1994).

${ }^{2}$ See for instance Buffit et al. (2007) for an analysis of medical clusters or Fromhold-Eisebith (2008) for the automotive industry clusters.

${ }^{3}$ For other European studies see European Commission (2002) and Euricur (2004).
} 
information and communication technologies (ICT), medical equipment, and communication equipment. Initiatives emerge from the public and industrial sectors or both, although the public sector always plays a fundamental role ${ }^{4}$.

\section{Objective of the Research}

The study originated from a research requested by the company 22@Barcelona, which wanted to position the economic district it manages in an international context (Bosch et al. 2008). The 22@Barcelona currently concentrates companies, research institutes and public administration in Media, ICT, biomedicine and energy areas, in a cluster-like fashion. To establish whether this initiative can respond to the challenges posed to the local economy of Barcelona by the knowledge-based and globalized economy, it was necessary to compare it with other similar initiatives.

Based on the previously described theories of clusters and innovation, this paper analyzes how they were created, how they are managed and how they operate, and the strategies followed to improve and excel in their fields of action. Particular attention has been made to aspects related to descriptive issues, research and development (R\&D), performance of clusters, location factors and incentives to attract companies. These clusters have to be understood as an industrial system consisting of players, resources and activities joining together to develop various types of goods and services, or as a spatial agglomeration of certain economic sectors.

\section{Methodology}

First of all, based on the following selection criteria, 22 clusters have been identified from around the world (Figure 1), located in 18 different countries of Europe, America and Asia:

1. Content dimension: the cluster must be specialized in at least one of the four activities carried out in the 22@ District: ITC, media, medical technologies (TecMed) and energy.

2. Urban dimension: the cluster must be located in a city or in a metropolitan region.

3. Geographic diversity: the cluster can be located anywhere in the world, as long as it meets at least one of the previous dimensions.

4. Excellency criteria: the cluster must be well positioned at international level, and be acknowledged as a successful case in its field of action.

When analyzing the data, the study has combined quantitative and qualitative methods, depending on the information to be processed. The data collection was done through a selection of indicators chosen in order to cover the different elements that cluster literature coincide in consider essential to develop a competitive economic cluster in urban regions (Koschatzky and Lo 2007, Sölvell, Lindtqvist and Ketels 2003, European Commission 2002, Euricur 2004). Five sets of indicators have been used, chosen to enable the evaluation of each of the districts and their comparison: descriptive indicators, $R \& D$, performance, location factors and public incentives. Due to the diversity of information sources, we have decided to use the last year available in each variable.

\footnotetext{
${ }^{4}$ For a critical analysis on the role of public administration in cluster's development see Desrochers and Sauet (2004).
} 


\begin{tabular}{|c|c|c|}
\hline Cluster & Region / City & Country \\
\hline Canary Wharf & London & United Kingdom \\
\hline Digital Hub Dublin & Dublin & Ireland \\
\hline Discovery District Toronto & Toronto & Canada \\
\hline Dubai Internet City & Dubai & Arab Emirates \\
\hline $\begin{array}{l}\text { Electrum and Kista Science Park } \\
\text { Stockholm }\end{array}$ & Stockholm & Sweden \\
\hline Enterprise Seattle & Seattle & USA \\
\hline Forum Virium Helsinki & Helsinski & Finland \\
\hline Hafen City Hamburg & Hamburg & Germany \\
\hline HighTech Campus Eindhoven & Eindhoven & The Netherlands \\
\hline Hsinchu Science Part Taiwan & Taiwan & Taiwan \\
\hline Knowlege Innovation Community Yangpu & Shanghai & China \\
\hline Life Science Cluster Boston & Massachusetts & USA \\
\hline Liverpool Digital & Liverpool & Unkited Kingdom \\
\hline Manchester Knowlege Capital & Manchester & United Kingdom \\
\hline Munich Biotech Cluster & Munich & Germany \\
\hline Novi Science Park Aalborg & Aalborg & Denmark \\
\hline One North Singapore & Singapore & Singapore \\
\hline Oresund IT & Oresund & Denmark/Sweden \\
\hline Orlando Media Digital & Orlando & USA \\
\hline Rhône-Alpes Eco-Énergies & Rhône-Alpes & France \\
\hline Silicon Fen Cambridge Cluster & Cambridge & United Kingdom \\
\hline Torino Wireless & Torino & Italy \\
\hline $22 @$ & Barcelona & Spain \\
\hline
\end{tabular}

Figure 1: List of Selected Clusters

To collect information about the clusters, a questionnaire that included all the points considered essential to the comparative analysis was sent by e-mail to the 22 clusters under study and we received ten replies. Regarding the cases that did not reply, the main source of information has been research work in the internet, and, whenever possible, data has been checked by consulting various sources (web pages, articles in scientific magazines, newspapers, reports, analyses made by consultants, etc.). For statistical data of countries and regions, we have consulted the web pages of Eurostat, OECD, and the National Science Foundation.

\section{Comparative Description of the Clusters}

The majority of clusters are located in Europe, followed by Asia and North America. More than half of the chosen clusters have been recently created, from 2000 (14), some are older, from the eighties (3), and nineties (3), and three were created before 1980. 
In more than half the clusters (15), the geographic distribution of businesses and institutions is limited to a well defined area, while there are others (8) where businesses are spread out over a larger extension without a clear physical delimitation. The dimension of clusters with a physical delimitation varies between 1.5 and 625 hectares, the largest being the Hsinchu Science Park in Asia. All urban clusters covering less than 10 hectares are located in Europe.

The number of businesses varies between 20 and 12,000. The Forum Virium Helsinki is the smallest (this is a newly created cluster), but the majority of its companies are large and medium-sized, similar to the case of Canary Wharf London. The remaining clusters have small and medium-sized businesses, although all have some large companies which are leaders in the activity sector of the cluster. With regard to the number of employees, nine of the clusters have less than 10,000, while four have between 10,000 and 30,000 employees, including 22@Barcelona.

The number of clusters incorporating more than one economic sector is similar to those focusing on one particular sector, with the majority specializing in ITC activities (15) and biotechnology (12), six include media activities and only three have companies of the energy industry.

The majority of clusters are a result of public (ten clusters) or private (seven) initiatives and five are mixed. Only one is a university initiative, which is the Cambridge cluster. It should also be mentioned that many clusters conceived from the private sector have received public backing, and in some cases, the European Union has participated through the Interreg programmes. Besides the type of initiative, a close relation between the regional development agency and the management institution of the cluster is relevant for a better coordination of the public and private agents, as we see in EnterpriseSeattle and One-North Singapore, where both institutions are the same one.

In the majority of clusters there are more mature companies than start-ups or spin-offs, with the exception of Novi Science Park Aalborg, which is characterized precisely as being a park for start-up companies which want to expand. Life Science Boston, which specializes in biotechnology, has also a high number of start-ups.

With respect to related institutions, regional clusters have a greater variety than those with a clear physical delimitation, among which Munich Biotech and Discovery District appear to be the best positioned. Regional clusters with the highest score in the number of linked companies are Life Science and Øresund IT.

Evolution statistics of clusters are difficult to compare, as the periods indicated by each one are not the same, and also the variable used is different in each case. For all clusters providing details, evolution has been positive, with the exception of Silicon Fen. Some have experienced very significant expansion, such as the case of Munich Biotech and Digital Hub Dublin. A total of 1,063 companies have set up in 22@Barcelona over the period 2000-2007, more than half of which operate in one of the four strategic sectors (media, ITC, TecMed and energy). All clusters in the USA have increased in recent years, both in the number of occupancies and in the volume of sales.

\section{Research and Development}

$\mathrm{R} \& \mathrm{D}$ is acknowledged as one of the backbones forming a cluster, either as one of the condition factors of the competitiveness model of Michael Porter $(1985,1990)$ or as one of the parts of the triple helix, where the interaction between universities, government 
and companies is the key to the promotion of technological innovation (Mohnen 2005). The new trend in knowledge creation tends to eliminate the strong boundaries between separate institutional spheres and organizations leading to a more flexible overlapping system (Etzkowitz 2002). In fact, the improved university - private sector relationship focuses on a large part of $R \& D$ promotion policies, and therefore, various measures are developed from public administrations to improve this cooperation, such as grants and subsidies to research projects, the promotion and marketing of scientific results or the direct financing of new R\&D infrastructures.

Questions related to $R \& D$ in this study have focused on the presence or absence of seven elements: R\&D projects, generation of spin-offs, ongoing training programmes, laboratories and experiment areas, joint educational programmes, creation of start-ups and technology transfer. The data discussed in this article are focused exclusively on activities performed directly in the cluster itself.

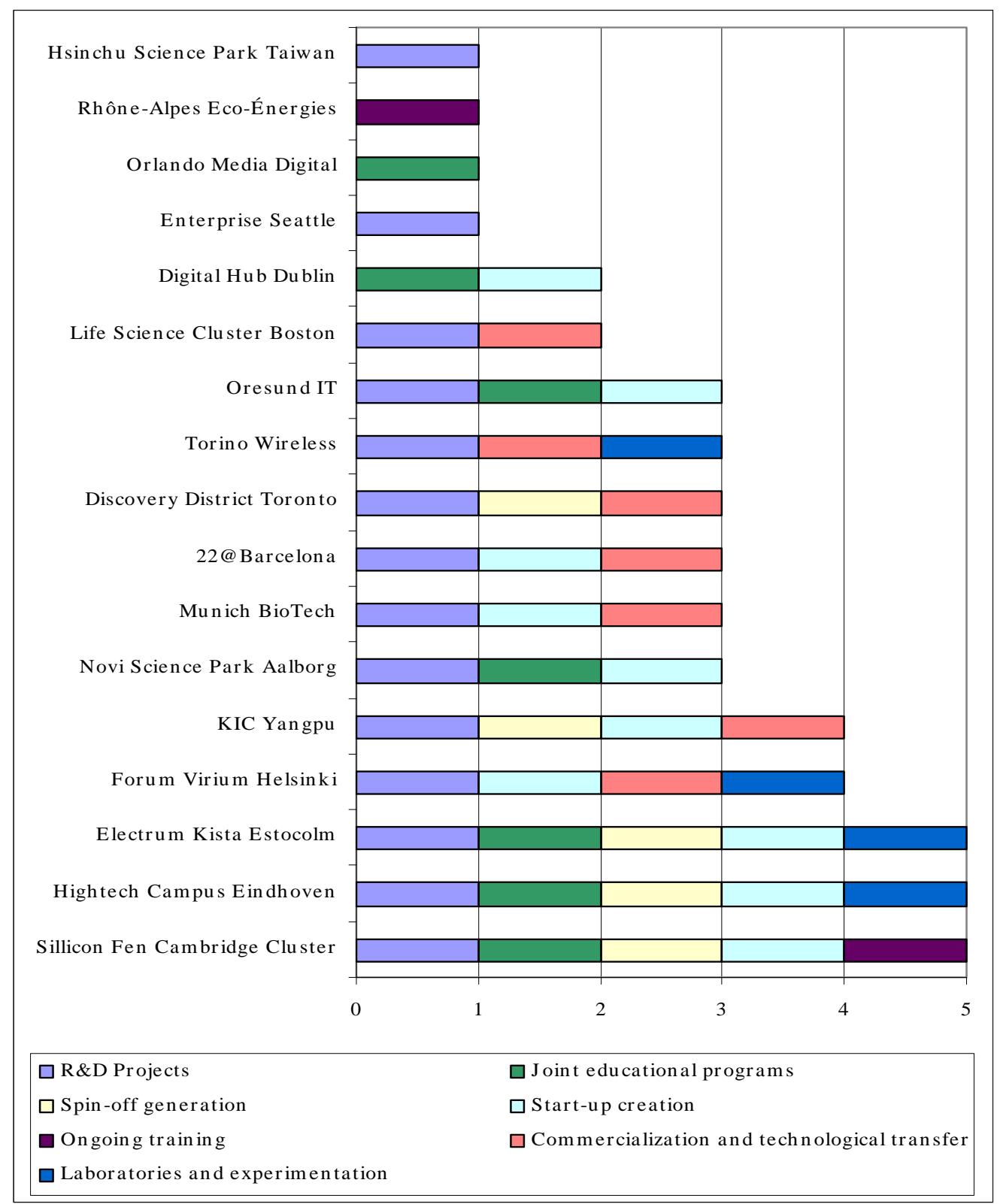

Figure: 2 Activities Related to R\&D within the Cluster 
Firstly, we should mention that all the clusters analyzed refer to R\&D activities. The clusters of Silicon Fen Cambridge and High Tech Campus Eindhoven stand out as having the highest number of R\&D activities and they can be considered the best in this aspect (Figure 1). Cambridge stands out for its ongoing training activities also offered to employees of the cluster, and Eindhoven for its laboratories, where companies can experiment prototypes and safely perform experiments at low cost. After these two cases, Forum Virium Helsinki, Electrum Kista Science Park Stockholm and Knowledge Innovation Yangpu focus on four of the activities related to R\&D. Forum Virium Helsinki particularly stands out for marketing research results and Electrum-Kista Science Park Stockholm for its joint educational programmes with universities. In any event, the majority of clusters has an applied approach to R\&D and tries to promote it as much as possible, such as Discovery District Toronto, Wireless Turin and 22@Barcelona.

Another form of R\&D identified in some clusters is the presence of laboratories, where small companies and also university researchers can draw-up models or directly develop prototypes for future application in real life, such as in the case of Electrum-Kista Stockholm.

Joint research projects between universities and companies have been identified in eleven of the clusters. Many of them also have joint educational programmes, such as the Eco-Energies Rhône-Alpes cluster. However, ongoing training from the university directed at businessmen or employees of the cluster are less developed, with only one programme identified in Silicon Fen Cambridge. Support programmes to the creation of spin-offs and start-ups are more frequent, such as the case of Silicon Fen Cambridge, HighTech Campus Eindhoven, Discovery District Toronto, Digital Hub Dublin, 22@Barcelona, Øresund IT and Novi Science Park Aalborg.

Another significant cluster in terms of $R \& D$ is Øresund IT, which stands out for its high proportion of qualified manpower (6.500 Ph.D. students), for multidisciplinary $\mathrm{R} \& \mathrm{D}$ programmes and for the high number of scientific publications related to IT issues and its significant increase (47 per cent from 2002 to 2003).

The 22@Barcelona cluster is in a relatively good position, in a positive regional context with one of the highest private investment in $R \& D$ in Europe and good infrastructures to develop the triple helix and university-company research projects. However, it has some weak points, such as the low investment in R\&D by public administrations and the low number of companies performing internal R\&D activities (a third in 2006). Another problem is that many areas dedicated to $R \& D$ are not yet operational, although this should be solved shortly.

\section{Performance}

The concept of performance refers to the operation of the cluster, which are the key elements capable of boosting the use of external factors generated in the proximity. The factors which have been detected are classified in three aspects: support to companies, the attraction of private capital and networks.

\section{Support to Companies}

A number of elements of support have been identified and assessed: if the cluster provides professional, legal, technical and financial advice, the services present in the cluster, and provision of facilities and resources to facilitate communication among companies. At least 75 per cent of the elements studied are present in practically half the 
clusters, which reinforces the idea of considering them as a necessary condition to the operation of clusters.

Clusters with best results are located in different geographic areas, and therefore, it is possible to formulate the hypothesis that the keys in the dynamics of business support in clusters could form a general pattern.

The positioning of de 22@Barcelona compared to the remaining clusters is good, as the Landing and UGAP (Management Unit of Aid to Projects) programmes enable the district to be at the same level as clusters highlighted for this aspect.

\section{Attraction of Private Capital}

Start-ups and growing companies need to have sufficient resources to perform their operations and therefore require financing to be able to develop the product, the market penetration and investments, and sufficient cash flow to ensure their operational continuity. Clusters have been classified according to their main source of attraction of private capital, which is a key factor to their development and growth.

Most of the clusters make use of private capital attracted by entities of their city or region, such as the case of Digital Hub Dublin or Øresund IT. This method of attracting funds is also found in many cases as a secondary way of accessing capital.

Clusters that have been able to develop their own initiatives to attract private capital have responded better to the needs of companies due to the proximity of end users of financing, such as the case of the initiative 22@CAPITAL. Nevertheless, the majority of these initiatives have received the backing of their respective local or regional governments, which proves the need for relations with a public partnership.

Alternative ways of generating attracting forces include the cases of Dubai Internet City, for its financial incentives, Life Science Cluster Boston as it is located in a know-how pole acknowledged throughout the world, or Forum Virium Helsinki for the major companies located there (Nokia and Microsoft) with their own capital risk services.

\section{Networks}

The different collaboration networks present in the clusters have been classified according to type and players taking part in them, in order to view the transmission of know-how and know-who within each cluster. Networks have been identified in seven levels, which are represented in Figure 3. It is important to notice that not all the networks have the same relevance, being more important those referring to $R \& D$, innovation or production than the informal networks.

Three profiles can be clearly identified of who was the driving force behind the creation of the network. The first is when the cluster itself promotes and establishes networks in a much centralized fashion, normally when the public sector is directly involved in the creation and functioning of the cluster, such as the case of Hsinchu Science Park Taiwan. Another case is when the players become involved naturally and the manager of the cluster acts as a shadow agent providing all the means for initiatives to be set up successfully, such as the case of Kista Science City Stockholm. The last profile is when these resources are outsourced taking advantage of already existing networks, such as Munich Biotech with the EurOffice Services Network.

In 70 per cent of the cases, Internet was the main source for network activities (i.e. marketing, business relations). We should mention that almost half the clusters 
have intranet for the circulation of information among members, such as the case of Barcelona with 22@Network.

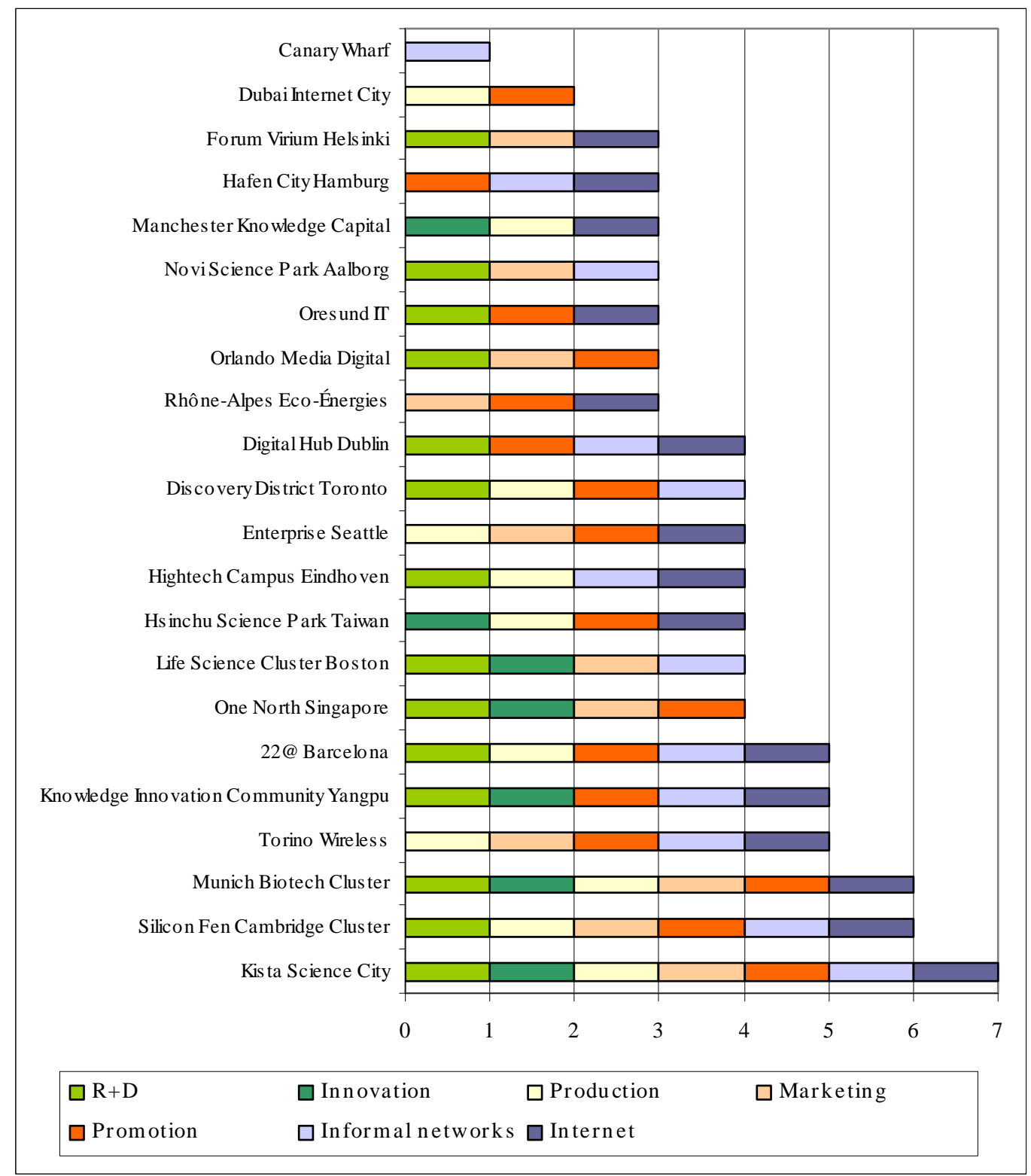

Figure 3: Types of Networks in the Cluster

Regarding the players involved in the different networks, a clear prevalence of the networks established among companies can be observed. Contrary, there are a relatively low number of clusters which achieve networks involving all agents.

The overall operation of cluster networks is better as the involvement of players making up the triple helix increases. It is also essential establishing networks between professionals given the importance of retaining talent and to offset the high rotation of employees working in know-how intensive sectors. 


\section{Location Factors}

Location factors have been studied based on the data available, which have been taken from several sources: the questionnaires that were sent to the clusters, Eurostat for European clusters and various observatories for the rest.

As regards accessibility, Barcelona is in the top part of the ranking (considering elements such as airports, ports, highways). Since it is a significant node of activity in the Mediterranean arc, it has many infrastructural elements that place it within the most accessible cities in the world. However, it should improve on the number of intercontinental flights from the airport, which, on the other hand, is well connected to other European airports. It should also be noted that other cities of similar size have at least two airports.

To understand the size of the local market, the population of the agglomeration of cities or areas where clusters are located has been used. The analysis of data has enabled us to see how the size of the market and its accessibility can be placed parallel, as the larger an urban agglomeration, the more accessible it is.

Certain exceptions can be observed, such as the case of Stockholm, one of the most accessible cities, but with a population of less than two million, which is between Orlando and Liverpool, two cities with relatively low accessibility. The agglomeration of Barcelona is placed in the highest part of the classification, with five million inhabitants, which is similar to two major metropolises, one in Asia, namely Singapore, and the other in North America, namely Toronto.

Although it has not been possible to carry out a full analysis, due to the lack of data, it should be mentioned that Barcelona is also positioned in an average position in comparison with other cities throughout the world regarding costs for companies, such as rentals of offices, retail establishments and industrial land, or gas and electricity for industrial use (Observatori de Barcelona 2007).

One of the main attractions of Barcelona lies in combining a high quality of life with relatively low costs within an international context. Regarding the first of these factors, we should underline that professionals interviewed by European Cities Monitor have chosen Barcelona for ten years running as the European city offering the best quality of life to its employees (Cushman \& Wakefield 2008).

\section{Public Incentives}

Public incentives to companies could be defined as a set of policies designed by the public administration to make a location more attractive to investors/businesses. Nevertheless a public cluster policy can also give rise to inertia, political game playing and opportunism (Burfitt et al. 2007).

Therefore, these incentives are localization factors which do not correspond to the advantages of the place and also they may be targeted at attracting companies from a specific economic field. The most common are tax or financial incentives, or noneconomic incentives, such as legal advice, and grants for infrastructures or services. (Rondinelli and Burpitt 2000).

In this study, we have analyzed public incentives from two aspects: those offered by regions and cities to which the clusters under study belong; and those offered exclusively by the cluster itself. The analysis has found that although some incentives are exclusively the responsibility of the states (for example company tax deductions), others can be offered by any of the administrative levels analyzed, such as the case of financial incentives for start-ups. There are also incentives which whoever sets them up, 
can be targeted exclusively to the cluster, or be of a general nature for all companies wanting to establish themselves in a certain country, and which will therefore also indirectly benefit companies installed in the cluster of that country.

The first result shows that in all cases studied, deductions are offered for R\&D activities, and credits and financial facilities for start-ups. Deductions for R\&D activities are established especially by state authorities, although in the case of Toronto, Boston and Barcelona, they are also offered by regional governments or by the cluster itself. Asian countries are different from Western countries, as in the cases studied; they are offering tax exemptions and free trade areas which western states do not have. Other relevant incentives found at different degrees in the cases under study, are aid to young companies and venture funds to create and localize businesses.

Those incentives that are not of an economic nature are offered in some of the cases studied. For example, in France, they are trying to make administrative procedures needed to create new companies simpler, and in Taiwan they are also simplifying town planning permission to install companies in the Hsinchu cluster. In other cases, it is the regional administration offering incentives directed specifically at developing activities of clusters. This is the case of the region of Noordbrabant in the Netherlands, the Northwest region in the United Kingdom, and the Northjutland region in Denmark, which all have non-economic incentives such as legal advice for companies seeking to establish themselves in their respective clusters.

The 22@Barcelona cluster appears to be in a relatively weak position as regards public incentives, as when compared to other clusters, it only stands out for noneconomic incentives. At state level, Spain offers the most favourable tax incentives in the world for foreign share companies, while Catalonia provides financial aid to create companies and to develop SMEs, but does not have a programme specifically targeted at22@Barcelona.

\section{Final Considerations}

The fact that the analysis had to be done mainly from a qualitative perspective and with information that does not always include all the clusters makes it difficult to set a global ranking from the indicators used. However, we have been able to place the Barcelona district in its context for each of the aforementioned variables, enabling us to assure that the international position of 22@Barcelona is generally good.

Another problem encountered with the information available to carry out this study has been its heterogeneity. The variability of data available from one cluster to another has made it difficult to establish common 'behavioural' models due to different experiences, and therefore to group innovative districts according to certain characteristics. This methodological difficulty has been also highlighted by Desrochers and Sautet (2004) when they conclude that the data may be biased by the background of the informants and the quality of the data available.

Our research also contributes to the discussion on the role of public institutions in the cluster development policies (Burfitt et al. 2007). In the clusters studied here, especially in 22@Barcelona, we have seen that a capable and resourceful public administration can determine the success of the cluster initiative. This line of research should be reinforced with more intercontinental comparison of clusters as the one undertaken here to fulfil the scarcity of such studies. 


\section{References}

Bresnahan, T., Gambardella, A. and Saxenian, A. 2000. Old economy inputs for 'new economy' outputs: Cluster formation in the new Silicon Valleys. Industrial Corporate Change, 10(4), 835-860.

Bosch, J., Capel, L., Cougoule, F., Ferrari, G. and Solans, S. 2008. El Projecte 22@Barcelona: Situación actual i comparacions internacionals. Document de Treball, 37. Barcelona: Institut d'Estudis Territorials.

Burfitt, A., Macneill S. and Gibney, J. 2007. The dilemmas of operationalizing cluster policy: The medical technology cluster in the West Midlands. European Planning Studies, 15(9), 1273-1290.

Cushman \& Wakefield 2008. European City Monitor 2007. Available online at: www.europeancitymonitor.eu [accessed: 14 June 2010].

Desrochers, P. and Sautet, F. 2004. Cluster-based economic strategy, facilitation policy and the market process. The Review of Austrian Economics, 17, 233-245.

European Commission 2002. Regional clusters in Europe. Observatory of European SMEs, 3. Available online at:

http://ec.europa.eu/regional_policy/innovation/pdf/library/regional_clusters.pdf [accessed: 14 June 2010].

Etzkowitz, H. 2002. The Triple Helix of University - Industry - Government Implications for Policy and Evaluation. Working paper 2002(11). Stockholm: Institutet för Studier av Utbildning och Forskning.

Euricur 2004. ICT Clusters in European Cities During the 1990 (MUTEIS Project, European Commission IST-2000-3011).

Fromhold-Eisebith, M. and Eisebith, G. 2005. How to institutionalize innovative clusters? Comparing explicit top-down and implicit bottom-up approaches. Research Policy, 34, 1250-1268.

Fromhold-Eisebith, M. and Eisebith, G. 2008. Looking behind facades: Evaluating effects of (automotive) cluster promotion. Regional Studies, 42, 1343-1356.

Koschatzky, K. and Lo, V. 2007. Methodological Framework for Cluster Analyses, Working papers firms and region R1/2007. Karlsruhe: Fraunhofer ISI.

Krugman, P. 1991. Geography and Trade. MIT Press: Cambridge, MA.

Leamer, E. and Storper, M. 2001. The Economic Geography of the Internet Age. Journal of International Business Studies, 32(4), 641-665.

Mohnen, P. 2005. The Importance of R\&D: Is The Barcelona 3\% a Reasonable Target. Available online at: http://arno.unimaas.nl/show.cgi?fid=12766 [accessed: 14 June 2010].

Observatori de Barcelona 2007. Informe 2006 i 2007 (Ajuntament de Barcelona i Cambra de Comerç de Barcelona).

Porter, M. 1985. Competitive Advantage: Creating and Sustaining Superior Performance. New York: Free Press.

Porter, M. 1998. Clusters and the new economics of competition. Harvard Business Review, Nov-Dec, 77-90.

Porter, M. 1990. The Competitive Advantage of Nations. New York: Free Press.

Rondinelli, D. and Burpitt, W. 2000. Do government incentives attract and retain international investment? A study of foreign-owned firms in North Carolina. Policy Sciences, 33, 181-205.

Saxenian, A. 1994. Regional Advantage. Culture and Competition in Silicon Valley and Route 128. Cambridge, MA: Harvard University Press. 
Sölvell, Ö., Lindtqvist, G., and Ketels, C. 2003. The Cluster Initiative Greenbook. Available online at: www.isc.hbs.edu/Greenbook.htm [accessed: 14 June 2010]. Storper, M. and Walker, R. 1989. The Capitalist Imperative: Territory, Technology and Industrial Growth. Basil: Blackwell. 